\title{
REFLEXÕES EM TORNO DE UMA FORMAÇÃO EM ANIMAÇÃO TEATRAL
}

MARIA FLOR DIAS

Instituto de Educação - Universidade do Minho

\section{CARLA PIRES ANTUNES}

Instituto de Educação - Universidade do Minho

RESUMO O presente texto reúne um conjunto de reflexões elaboradas em torno da experiência do primeiro ano de implementação do Mestrado de Animação Teatral do Instituto de Educação da Universidade do Minho. Debruça-se sobre a estrutura curricular deste curso, de modo particular sobre aquela que é por excelência a sua unidade curricular eixo, Estudos Performativos. O texto problematiza as questões fundamentais que orientaram o travejamento conteudinal dos Estudos Performativos e o modo como nesta unidade de conhecimento se procurou articular preocupações epistemológicas e de ensino e aprendizagem e, simultaneamente, responder às necessidades inerentes à heterogeneidade do público alvo, no que se refere à sua formação inicial, aos diferentes sentidos e graus de literacia e fruição teatral. Finalmente, reflete sobre os blocos conteudinais da unidade curricular que melhor ilustram o sentido de pesquisa teatral que a desconstrução e o uso do conceito de performance nos permitiram convocar no contexto de formação.

Palavras-chave: Animação Teatral. Animador Teatral. Formação. Estudos Performativos.

This paper presents a set of reflections made in relation to experiences that happened in the first year of the first course for the Masters Degree in Theatrical Activities in the Institute of Education, University of Minho. It looks at the curricular structure of this course and focuses especially on the course backbone - Performance Studies. The text discusses the fundamental questions that guided the content framework of Performance Studies and the way that this unit of knowledge sought to articulate epistemological, 
teaching and learning concerns, while simultaneously meeting the inherent heterogeneous needs of the target audience; namely, in relation to the initial training of students, their different goals, as well as their degrees of theatrical literacy and experience. Finally, it reflects on the constituent modules of the curricular unit that best illustrates the goals of the theatrical research opened up by the deconstruction and use of the concept of performance in the training context.

Keywords: Theatrical Activities. Theatrical Animateur. Training. Performance Studies.

\section{RESUMEN REFLEXIONES EN TORNO A UNA FORMACIÓN EN ANIMACIÓN TEATRAL}

El presente trabajo reúne un conjunto de reflexiones centradas en la experiencia del primer año de desarrollo del Máster de Animación Teatral del Instituto de Educación de la Universidade do Minho. Se detalla la estructura curricular de este curso, particularmente la de aquella que es, por excelencia, su unidad curricular vertebral: Estudios de la Interpretación. El trabajo polemiza en torno a las cuestiones básicas que orientaron la estructuración de los contenidos de los Estudios de la Interpretación y en torno al modo como, en esta unidad de conocimiento, se intentaron articular simultáneamente preocupaciones de tipo epistemológico y de enseñanza/aprendizaje, de un lado, y necesidades inherentes a la heterogeneidad de los destinatarios en lo referente a su formación previa y a su diferente sentido y nivel de conocimiento práctico y disfrute del teatro, de otro lado. Finalmente, el trabajo reflexiona sobre los bloques de contenido de la unidad curricular que mejor ilustran el sentido de investigación teatral al que la deconstrucción y el uso del concepto de interpretación nos permitieron acceder en el contexto de formación.

Palabras clave: Animación teatral. Animador Teatral. Formación. Estudios de la Interpretación.

Ausente da esfera dos grandes debates educacionais, esporadicamente sinalizada nas reformas educativas, ou ciclicamente convocada pela agenda das grandes fundações e organizações culturais internacionais, a Educação Artística, nomeadamente, o Teatro/Educação, foi-se posicionando tangencialmente à agenda política que, em grande medida, tem dirigido a investigação educacional em Portugal (DIAS, 2010).

Porém, nos últimos anos, esta tendência tem vindo a alterar-se. Um conjunto signi- 
ficativo de conferências, nacionais e internacionais, como o Roteiro Para a Educação Artística, "Roteiro Para a Educação Artística" (UNESCO, 2006), o “European \& International Research Symposium" (2007) subordinado ao tema "Evaluating the Impact of Arts \& Cultural Education on Children and Young People", a "Conferência Nacional de Educação Artística" (2007-2008) e os estudos científicos e relatórios oficiais, nacionais e internacionais, como o "Report of the Task Force on the Arts" (2008), produziram informação crítica relevante sobre a situação do ensino em educação artística, bem como sobre as novas orientações a imprimir-lhe.

No plano nacional o "Estudo de Avaliação do Ensino Artístico" (2007) destacou a tendência para a consolidação e a a expansão do sistema de ensino artístico e da sua própria oferta educativa. Tal facto, revelado pela análise comparada de indicadores nacionais e internacionais, veio legitimar o discurso da investigação em artes e o da formação de nível superior (mestrados e doutoramentos) de modo a que os diferentes domínios artísticos, nomeadamente o teatral, pudessem interagir e responder, por um lado, à emergência de novas "comunidades criativas" conectadas com as "indústrias culturais e criativas" (COMISSÃO EUROPEIA, 2010), às necessidades das chamadas "culturas juvenis" (PAIS, 2003) e às decorrentes do fenómeno do "envelhecimento global das populações" (HARPER, 2008) e, por outro, às especificidades veiculadas pelas políticas sociais, culturais e artísticas de traçado europeu.

Paralelamente, a investigação produzida no campo da Educação de Adultos e no da Animação Sociocultural tem evidenciado a importância dos Estudos Teatrais no plano da intervenção e democratização cultural. As ideias de participação e cidadania, implícitas na praxis da democratização cultural, comprometem as linguagens e formas teatrais com o desenvolvimento e a autonomia dos indivíduos na comunidade.

Foram, aliás, razões de ordem praxeológica e fundacional que levaram Ventosa (1996) a considerar o teatro como o instrumento operativo por excelência da Animação Sociocultural. Afirma o autor que, salvo como mera estrutura formal e teórica, a prática da Animação Sociocultural não poderá nunca, existir por si só. A natureza interventiva e o carácter operativo da animação obrigam a que se mobilizem espaços e se convoquem modelos de intervenção concretos, para que a Animação Sociocultural possa realmente se materializar. Entre os possiveis instrumentos e modelos de intervenção, o Teatro tem sido consensualmente assumido como referência duplamente fundacional: porque tempo único de criação individual e ou colectiva e porque locus de encontro e partilha da experiência de alteridade, historicamente inscritos no cerne identitário do Teatro.

$\mathrm{Na}$ confluência destes fatores, a possibilidade de criação de um Mestrado em Animação Teatral, no Instituto de Estudos da Criança da Universidade do Minho, representou uma oportunidade educativa importante. Alargava-se com ele a própria oferta formativa da instituição e, simultaneamente, agarrava-se a oportunidade histórica de fidelizar, nas geografias do conhecimento oficial da Academia, o que genericamente designamos por Estudos Teatrais.

As considerações acima referidas (algumas das quais com fortes implicações no plano epistemológico e na concepção curricular do curso), as próprias condicionantes institucionais e o suporte legal disponivel entreteceram e cunharam especificidades no desenho do plano curricular, daquele que seria o primeiro Mestrado em Animação Teatral desta Academia. 


\section{Perfil de Formação e Objectivos Gerais do Curso}

No que se refere ao perfil da formação académica superior, estabeleceu-se que este se deveria constituir como um processo que promovesse a inovação, o aprofundamento e a articulação dos conhecimentos, considerando a sua aplicabilidade no exercício de uma profissão.

Por meio dele, o aluno, protagonista do processo educativo, deveria adquirir competências necessárias à adopção de atitudes de reflexão, autonomia, cooperação e participação, resultados directos da flexibilidade da formação, da reciclagem e da reconversão dos conhecimentos, impulsionando-se, assim, a inovação e a transformação funcional e criativa.

Em termos de estrutura conceptual, um conjunto de conhecimentos fundamentariam a ação onde cada fundamentariam a ação, onde cada disciplina iria incorporar os métodos próprios, e cada docente incutiria o carácter dinâmico e evolutivo da estrutura disciplinar pela qual cientificamente o seu ensino responderia.

Em termos de objectivos gerais de formação, o ciclo de estudos do Mestrado deveria promover a aquisição de competências no domínio da Animação Teatral relevantes para os processos de intervenção e Animação Sociocultural. Para tal, impulsionar-se-ia o conhecimento de perspectivas teóricas e o debate sobre paradigmas da educação, animação e intervenção artística. De igual modo, se procuraria fornecer ao aluno as ferramentas básicas que the permitissem dominar os modelos de acção teatral e fomentar atitudes de trabalho colaborativo com os demais agentes socioeducativos, na construção, desenvolvimento e avaliação de projectos de educação, animação e intervenção artística, assim como no desenvolvimento, gestão e organização de eventos artístico-culturais, onde a família e a comunidade pudessem envolver-se. Pretendia-se, assim, responder aos grandes desafios do mundo actual, nomeadamente, o da construção de um futuro mais sustentável.

\section{Plano de Estudos e Estrutura do}

\section{Curso}

0 modelo de formação transcorreria em 4 semestres curriculares, distribuindo-se por estes, o curso de especialização propriamente dito e os trabalhos de seminário e investigação conducentes à elaboração da dissertação de Mestrado.

O plano de estudo convocaria o conjunto de Unidades Curriculares de natureza obrigatória e opcional, que se apresenta a seguir.

\section{Unidades Curriculares Opcionais}

1. Puppetry (Atelier de formas animadas)

2. Imagem, Som e Vídeo

3. Teatro Musical

4. Cidade, município e acção educativa e cultural

5. Estética e filosofia teatral

6. Formação e aprendizagem ao longo da vida 
O referido plano obedeceria ao princípio de articulação vertical e horizontal em termos de horizontal, em termos de relevância e flexibilidade, tanto a nível dos conteúdos, como das metodologias e sistemas de avaliação, tendo em conta o objeto de estudo e sua pertinência para o perfil de formação.

\section{Estudos Performativos: um Olhar Reflexivo Sobre a Unidade Curricular}

Como vimos, os Estudos Performativos I e os Estudos Performativos II, com continuidades implícitas entre si, designam a unidade de conhecimento de maior peso, do ponto de vista da pesquisa laboratorial teatral, no plano curricular do Mestrado em Animação Teatral.

A concepção e o nome dos Estudos Performativos são resultado de uma procura sistemática e de um encontro bem-sucedido entre um punhado de preocupações epistemológicas e curriculares inerentes a um Mestrado de especialidade e o facto de se poder convocar, do mundo das artes, instrumentos conceptuais e praxeológicos capazes de responder de forma consequente àquelas preocupações.

Colocados perante a proposta de concepção de um novo Mestrado, condicionados quer pelas lógicas curriculares, temporais e espaciais, do modelo de formação (em tudo avessas aos requisitos da dinâmica da pesquisa e criação teatrais), quer pela espectável heterogeneidade formativa dos futuros candidatos, a questão fundamental, a questão fundamental que então se colocava, era a de saber seleccionar e recortar, de entre as formas e os vários conteúdos artísticos disponíveis, os que melhor se ajustassem às contingências da realidade existente e respondessem à complexa e questionável ideia: que teatro na animação sociocultural?

De facto, quando se fala em teatro no âmbito da Animação Teatral, pressupõe-se um teatro que foge ao cannon da tradição, que resiste à inclusão na "cultura cultivada" (CHARTIER, 2001); um teatro que surge indissociável da vivência pessoal dos indivíduos e da sua realidade social, razão pela qual, neste contexto, o "espectáculo teatral" não constitui de per se, a finalidade última, mas antes, um meio de re ligar, de pôr em comum. Trata-se de um teatro "ritual purificador no qual uma colectividade é posta em plena posse das energias que the são próprias (ARTAUD apud RANCIÈRE, 2010, p. 13); de um teatro que implica as pessoas, convocando-as, a si mesmas, como fazedores teatrais, e às suas experiências de vida, como razão de fazer teatro. Movem-se ali conceções de um fazer teatral que se preocupa com os indivíduos, que faz dos seus problemas e culturas motivos de texto dramático e referência educativa numa perspectiva de "diversidade, integração e educação multi e intercultural" (CARDOSO; LOPES; LEONIDO, 2004, p. 58).

Porém, este fluxo de vida real de que a animação teatral se alimenta e lhe é vital, em contextos de intervenção e democratização cultural, estará sempre (ao não se alterar nem se criar interstícios de ligação da Academia ao tecido social) ausente da experiência de formação do futuro animador teatral. Fundamentalmente porque a formação em animação teatral, ao ser implementada na Academia, longe da comunidade viva, fica subordinada às lógicas daquela, sujeita à fragmentação e à à pulverização do seu tempo e ao espartilho das racionalidades institucionais que são cada vez menos de cariz humanista e mais industrializadas. Pela mesma razão, também a convocação da realidade social, essencial aos processos de formação e criação teatrais, ficaria cativa do ethos académico e confinada a níveis de abstracção e à "ilusão da mimese" (RANCIÈRE, 2010), que mascaram a essência e o conflito inerentes à realidade social. Deste modo, 
o exercício da abstracção e o artifício, que se produzem sempre que se pretende problematizar e criar sobre o simulacro social, constituiriam, neste processo de contornos alienantes, os únicos retornos a serem presentes ao professor e ao aluno, no momento do balanço final. Serão, em última análise, projectos artificiais que ocorrem sempre que o formando é chamado a conceber e desenvolver projectos teatrais em função de enquadramentos sociais cujos limites e complexidades desconhece e com os quais, muitas vezes, não teve nem terá, contacto algum.

A maior parte dos formandos terá na melhor das hipóteses, um contacto débil com determinados contextos socioculturais, uma quase ausência de habitus de fruição cultural e um relativo afastamento dos loci de produção e distribuição artística. Acrescem a estes, condicionalismos inerentes a fatores económicos e ao tempo dispendido na enorme distância que os mantêm rotineiramente presos a um triângulo cujos vértices são quase invariavelmente Trabalho - Casa - Formação.

Nesta quase ficção, a unidade curricular, responsável pelo eixo teatral da formação, corria o risco de asfixiar, já que nem a "realidade real" poderia insuflar e informar os processos criativos, nem o formando, imerso neste faz de conta, poderia apurar do impacto social da sua intervenção, nem se apropriar do seu potencial capital criativo. 0 próprio reportar da experiência e das aprendizagens adquiridas (inerente aos dispositivos de avaliação e formação académicas), ficaria também ele hipotecado às inverdades de uma intervenção efabulada sobre o abstracto subjectivo.

Por outro lado, a grande parte dos registos escritos relativos a contextos e práticas teatrais de formação é orientada para textos de autor e a técnicas associadas à representação teatral - a voz, o corpo, a personagem, o ator e o teatro, desenvolvidas numa perspec- tiva direccionada ao espectáculo profissional e comercial. De igual modo, a experiência pessoal que o teatro proporciona a cada um dos atores intervenientes, em tudo distinta da experienciada em contextos de animação, não é normalmente alvo de reflexão escrita, ficando cativa dos segredos do ator, até porque, como refere Aslan (2010: XV), "ele não tem necessidade nenhuma de esclarecer para nós, a gestação obscura e dolorida que o conduz ao fundo de si mesmo ou para fora de si". Pelo que, toda a aprendizagem assim adquirida é, quando muito, partilhada pela via da oralidade. Uma e outra destas formas de pouco servem a quem se adentra na formação em Animação Teatral. Sobretudo porque a maior parte das actividades que se dinamizam a nível de comunidades, no âmbito da animação teatral, se alimentam do vivido colectivo, privilegiam histórias de vida, dão sentido à memória pessoal, ao acidente e ou problema local, em detrimento de guiões pré-escritos por agentes exteriores ao grupo ou à comunidade. As actividades são processadas, em primeiro lugar, através da improvisação e só depois, coletivamente transformadas em representação teatral, sob a orientação de animadores teatrais ou de artistas profissionais (que podem ou não estar activos noutros tipos de teatro profissional), ou de artistas amadores locais, residentes entre o grupo de pessoas e que, por falta de um melhor termo, são muitas vezes chamados de "periféricos", como salienta van Erven (2001). No caso do teatro comunitário, este colhe os seus frutos naquelas performances em que os residentes da comunidade participam, envolvendo-se eles próprios, substancialmente, no processo criativo.

Este tipo de abordagem só muito raramente é captado pelos media nacionais e, porque ocorre frequentemente fora dos meios artísticos "legítimos", tende, por isso, a escapar à atenção dos teóricos da cultura, dos estudio- 
sos do teatro e aos da própria animação. Trata-se de um tipo de teatro que privilegia, em primeiro lugar, o prazer do fazer artístico e o empowerment dos seus participantes. As suas formas materiais e estéticas emergem directamente, se não exclusivamente "do" grupo ou "da" comunidade, cujos interesses tenta expressar, não havendo, por isso, grande reflexão teórica sobre esta temática (VAN ERVEN, 2001).

Identificado o quadro de contingências que rodeou a oferta educativa que constituiu a proposta de Mestrado, três pressupostos fundamentais orientaram as opções curriculares então tomadas:

- O primeiro apostava na necessidade de fazer descolar os candidatos de uma representação tradicional de teatro e do fazer teatral, para uma outra representação social, que thes permitisse problematizar o teatro, as formas de o provocar, de o dar a ver e sentir e, sobretudo, de o tornar instrumento de democratização cultural em contextos sociais diversificados.

- O segundo, condicionado aos princípios da aprendizagem e da criação teatrais, propunha orientar-se pela senda da realidade. Os formandos, embora perspectivando o devir de se tornarem, no colectivo, animadores teatrais, partiriam individualmente de um foco real/ concreto onde a vivência, a experiência e o conhecimento, construídos através de processos de desconstrução das ideias de ator, de teatro e dos seus fazeres, abririam a possibilidade de transposição didáctica para contextos sociais concretos e variados.

- O terceiro, obedecendo ao princípio de articulação vertical e horizontal inerente ao plano curricular, procuraria guiar a pesquisa através de incursões interdisciplinares, aos diferentes domínios do conhecimento e das técnicas configuradores do plano de estudos.

Entre a perspectiva de desconstrução teatral e a de desinstalação no campo da recep- ção foi ganhando forma o conceito de Estudos Performativos.

A literatura produzida à volta do conceito de performance evidencia o seu carácter polissémico. Entendida como forma de arte particular com génese no campo das artes visuais, a performance é reconhecida pela sua ductilidade, pelo seu carácter interventivo, pela vocação para a modificação das relações da arte, com os seus fazedores e receptores. Por outro lado, as possibilidades plásticas reveladas no encontro com o teatro têm posto a nu um potencial operacional e conceptual que nos pareceu capaz de responder ao conjunto de inquietações suscitadas pela construção da unidade curricular e pelas questões éticas implícitas na democratização cultural e na Animação Teatral.

Ancorados naquele conceito, procurámos, ao invés da experiência de fazer os formandos imergirem imergirem num repertório de autor, propor experiências que os impelissem a procurar novos dispositivos de criação e de questionamento e thes permitissem construir novas relações e atribuir novos significados a objetos, textos e imagens, não só históricos, mas também os que com eles coabitassem, ou mesmo, convocados da tradição.

Fidelizados à ideia-motor de performance como "linguagem de interface que transita entre os limites disciplinares" ou, como refere Cohen (1989, p. 116), como um "topos divergente que atravessa fronteiras", assumimos os Estudos Performativos como lugar privilegiado de experimentação.

A partir dele, os formandos seriam convidados a procurar caminhos: o de problematizar o corpo como forma de interpretar o mundo; o de o pesquisar na relação com os objetos e com os sentidos que daí se desprendessem; o caminho de interrogar a imagem (fotografia, vídeo) para a reinventar sob lógicas diversas ou, ainda, o de provocar a percepção, tentando 
ir além do senso comum, da visão óbvia, dada e estática do mundo e, sobretudo, da mimese.

Importava, para isso, desvelar a teatralidade inscrita na própria fisicalidade dos formandos. Na busca desta teatralidade, retardavase, intencionalmente, o encontro com a memorização do texto escrito; iludia-se o medo da palavra, com a surpresa da descoberta da teatralidade física. Deste modo, por um tempo, fisicalidade e imagética usurpariam o lugar privilegiado que, por tradição, a racionalidade da escrita teimou em ocupar na formação teatral.

$\mathrm{Na}$ pesquisa que antecedeu a concepção dos Estudos Performativos, procurámos autores que facilitassem a aproximação conceptual e experimental entre teatro, texto, corpo e imagem.

Para cada exercício, nomeadamente para os momentos, os performativos que tiveram como indutores a Imagem/Fotografia e o Objeto/Máscara, fizemos cruzar referências do campo visual e teatral. Interessou-nos o trabalho de Ribeiro (1997), pela aproximação entre Teatro físico e Performance. Como refere o autor, "o teatro físico como a performance corporal incita, não a ler as palavras - atitude para que tradicionalmente tendemos -, mas a ver as imagens. Pedem-nos, contudo, que as vejamos ultrapassando sua condição de informadores fidedignos da realidade e as tomemos como propostas que permitem a ficção e, nessa medida, um acrescento à realidade" (RIBEIRO, 1997, p. 124).

No plano da imagem, sustentámo-nos em autores que permitissem jogar com diferentes concepções e usos exploratórios da imagem fotográfica, nomeadamente Kossoy (1999 apud SILVA, 2008, p. 1), que desenvolve a ideia de que "a imagem de qualquer objeto ou situação documentada pode ser dramatizada ou estetizada, de acordo com a ênfase pretendida pelo fotógrafo em função da finalidade ou aplicação a que se destina".
Rosangela Rennó (2003) foi, entre os vários performers e investigadores (KOSSOY, 1999; SOUZA, 2001; SILVA, 2008), a referência conceptual para a primeira proposta de exploração performativa conduzida no âmbito dos estudos performativos Da Fotografia/Retrato/Às Personagens Retratadas

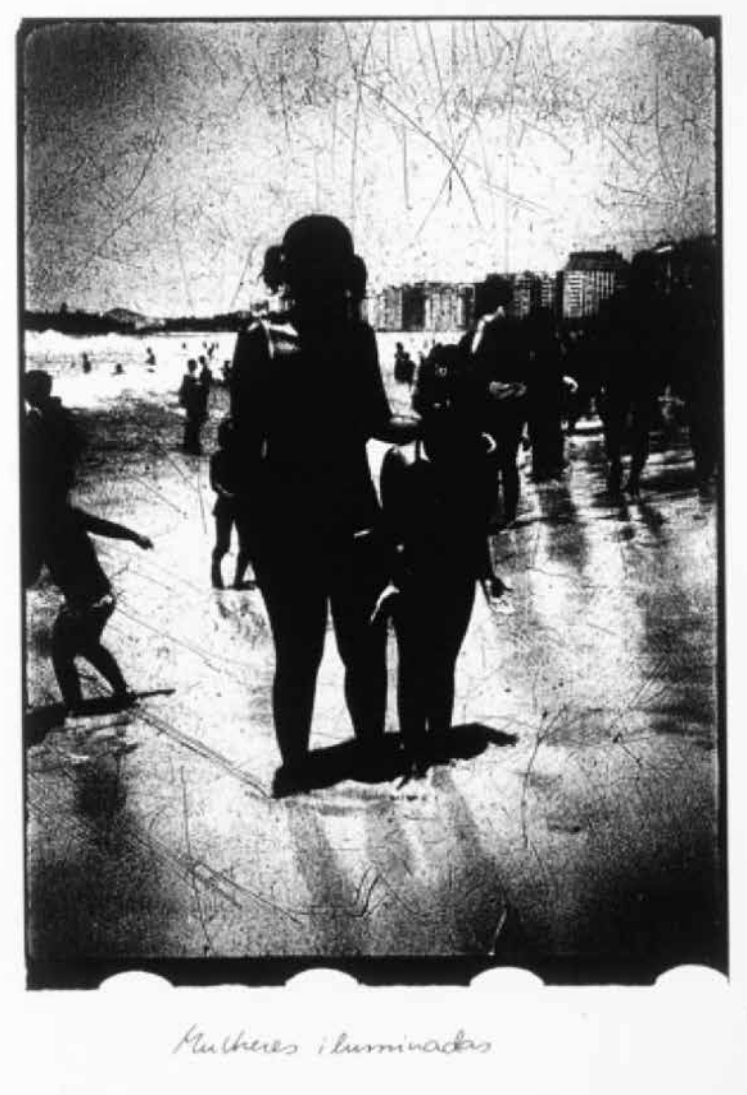

Rennó, Rosângela

Illuminated Women, 1988

Series "small ecology of the image"

Rennó (2003) reuniu num arquivo pessoal, fotografias de pessoas comuns e antigos álbuns de família, resultado da apropriação de arquivos alheios encontrados no lixo, comprados em feiras de antiguidades ou em arquivos públicos. Recorreu, também, a fotografias de notícias de jornais e obituários "para criar novas legendas, linguagem e significação daquele momento ou indivíduo e do que pode vir a representar posteriormente" (GONÇALVES; GONÇALVES, 2004, p. 7). Dificilmente produziu novas fotografias, trabalhou sobre as encon- 
tradas, sendo o seu trabalho, fundamentalmente, o resgate dessas imagens.

Desta artista, convocámos para a formação, a ideia/objeto de imagem fotográfica como indutora do processo de construção teatral. Do conjunto de fotografias disponiveis, recolhidas pelos formandos, interessava seleccionar não uma qualquer fotografia, mas uma de corpo inteiro, a preto e branco, inscrita num qualquer "cenário". Uma fotografia potencialmente produtora de subjectividades e de possiveis ressignificações das distintas realidades sociais inscritas naquela, ou que a sua pesquisa pudesse despoletar. Pertinentes para esta linha de pesquisa teatral foram também os contributos advindos da comunicação visual, ao enfatizarem a natureza multidireccionada que emanava das possiveis "leituras" da imagem fotográfica. Nesta perspectiva, a leitura da imagem podia ser feita ou pensada em termos simbólicos e iconográficos, sendo substancialmente diferente da leitura proposta pela palavra, valendo, neste caso, a imagem de per se.

Nas palavras de Souza (2001), a tessitura da imagem é dada pelo recorte de elementos pictóricos, associações de imagens, que não se prendem com influências ideológicas e são independentes da palavra. No entanto, a autora chama a atenção para que, à semelhança da interpretação verbal, a interpretação da imagem, e neste caso, da fotografia, pressupõe sempre uma relação com a cultura, com o social, o histórico, com a formação dos sujeitos.

Ao se interpretar a imagem pelo olhar - e não através da palavra - apreende-se a sua matéria significante em diferentes contextos. 0 resultado dessa interpretação é a produção de outras imagens (outros textos), produzidos pelo espectador a partir do carácter de incompletude inerente, eu diria, à linguagem verbal e não verbal. 0 carácter de incompletude da imagem, aponta, dentre outras coisas, a sua recursividade. Quando se recorta pelo olhar um dos elementos de uma imagem produz-se outra imagem, outro texto, sucessivamente e de forma plenamente infinita. Movimento totalmente inverso ao que ocorre com a linguagem verbal: quanto mais se segmenta a língua, menos ela significa. Daí não fazer sentido, numa abordagem discursiva, pensar a imagem, circunscrita numa moldura, como um todo coerente. (SOUZA, 2001, p. 5)

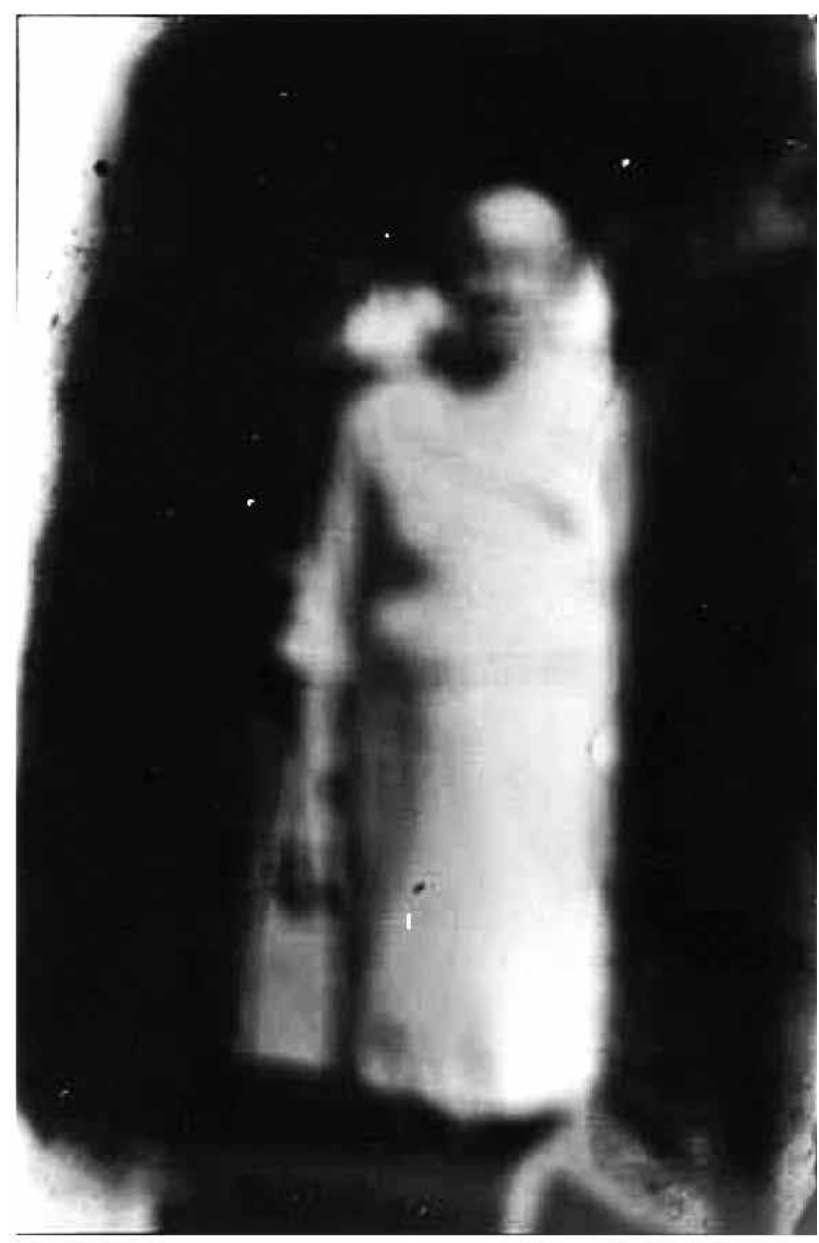

Rennó, Rosângela

The woman that lost the Memory, 1988

Small Ecology of the image

$35 \times 27 \mathrm{~cm} / 120 \times 90 \mathrm{~cm}$

Photographic Reproduction Rosângela Rennó

O carácter de incompletude a que a autora se refere relaciona-se com "o não dito", com o que está presente mas não é visível, com a intertextualidade, isto é, com os diferentes textos possíveis, em função do passado, presente e futuro, numa "leitura" carregada de simbolismo e de sentidos ideológicos e sociais. 0 potencial que esta incompletude encerra, impôs-se como um filão passivel de 
despoletar sentidos cujos limites posicionariam a escuta dos formandos na relação entre o corpo, a imagem fotográfica, a sua cultura e o texto.

A abertura inscrita na ambiguidade e na possibilidade do "não dito" foi orientando, de forma implícita, a senda por onde faríamos passar cada uma das pesquisas teatrais. Abriase, assim, espaço para cada formando usar, de entre o conjunto de fotografias disponiveis, a que, para si, revelasse maior potencial idiossincrático. Foi nesta conexão que a fotografia/ retrato se tornou visivel e passivel de ser teatralmente apropriada.

A "leitura" da fotografia/retrato escolhida pelo formando constituiu o primeiro indutor convocado para a criação da personagem. A vinculação à fotografia/retrato instigou o delinear de uma personagem. Entre os avanços e recuos dessa construção, a entrada de novos recursos (espaços, objetos, memórias e ações) permitiu que cada personagem crescesse e, com ela crescessem, também, itinerários onde aquelas se pudessem cruzar, interagir ou coabitar. Itinerários que funcionaram, para cada formando, como antecâmara de um compromisso com a personagem, urdida na relação entre espaço, corpo e texto.

O enredar das memórias das várias personagens deslocaria, pela improvisação, a construção individual, para a construção colectiva. Os alunos, organizados em três grupos de trabalho diferentes, teceram relações entre as personagens por si criadas, enredando-as em itinerários partilhados, fazendo emergir deste processo três significativas performances teatrais.

Emergiriam deste processo diferentes linhas de composição teatral que culminaram em três significativos exercícios performativos.

Os alunos, organizados em três grupos de trabalho, atribuíam significados diferentes às fotografias por si selecionadas, criando "no- vos retratos". Numa segunda fase, retocavam os "retratos", criando e definindo, progressivamente, novas identidades, diálogos, tempos e contornos que conduziram os grupos a diferentes cenas dramáticas.

O primeiro momento performativo (o interior de um autocarro) era visto como um "não -lugar" - um conceito desenvolvido pelo antropólogo francês Marc Augé (1995), um lugar neutro e transitório sem jurisdição, um lugar de passagem, de destinos incertos e conversas improváveis entre aqueles que "passando por" se encontram, tornou-se um lugar de confidências inimagináveis, revelações e partilha entre pessoas desconhecidas. Ao longo dessa "viagem", à medida que as personagens iam entrando e tomando o seu lugar, o assunto das conversas ia-se alterando, aumentava a tensão e aprofundava-se o conflito causado pelas revelações que iam sendo feitas pelos passageiros". Quando a personagem camera man entrou na cena, filmando tudo do lado de fora, a cena transmutou-se do teatral para o registro cinematográfico, criando assim um sentimento de estranhamento e nonsense.

O guião do segundo grupo construi-se em torno da traição e do feminismo. Os alunos criaram tipos sociais de mulheres de classe média-alta, cujas vidas se desenhavam em paisagens emocionalmente descoloridas e fechadas. Trancadas num tipo de gineceu, a determinada altura, as personagens perdem a compostura social e, num diálogo sem restrições, entre choros e gritos, acusam e insultam-se umas às outras por causa da traição de uma delas.

A cena proposta pelo terceiro grupo, duas mulheres e um homem, situada no pós-Guerra Colonial portuguesa desenvolvia-se num salão de chá. Neste encontro casual, cada personagem relembra momentos críticos da sua história de vida que desencadearam memórias que revelam uma partilha de um tempo comum. 


\section{Cabeçudos}

Para um segundo momento performativo, convocaram-se artefactos que tinham como característica serem identitários da festa popular e da tradição, mormente do norte de Portugal os Cabeçudos.

Cabeçudos e Gigantones habitam com igual à vontade um largo terreiro que a tradição inscreveu entre o profano e o religioso (CRUZ; LESSA; DIAS, 2008); sobretudo, eles incorporam hoje, esse enorme potencial de teatralidade ${ }^{1}$ (FÉRAL, 1982), ainda imanente à maioria das festas populares.

Inscritos na categoria estética do grotesco, os Cabeçudos ancoram teatralmente no espaço "entre", aquele onde a máscara (a grande máscara) e a forma animada se movem. A revelação do Cabeçudo no contexto performativo, já anteriormente identificado, poderia potenciar pesquisas direccionadas para a máscara, para a marionetização ou para outras, como a farsa e a comédia, esteticamente eivadas do gosto pela provocação e pelo excesso, típicos do grotesco.

Posicionados entre a Puppetry, onde foram previamente concebidos, e os Estudos Performativos, onde seriam propostos à exploração teatral, os Cabeçudos adequavam-se particularmente bem às orientações programáticas estabelecidas, garantindo os princípios de articulação e de coerência curricular cunhados no traço interdisciplinar requeridos pelo Mestrado. Para além de que a sua utilização poderia permitir desconstruir estereótipos e recolocar o formando numa nova relação de pesquisa do corpo e da sua fisicalidade com a dubiedade destas formas objectais.

Além disso, a proposta dos Cabeçudos retirava dividendos e dava continuidade a uma linha de investigação em educação artística já inscrita no Centro de Investigação do Insti-

1 Qualidade daquilo que tem condições cénicas para se representar (dic. port) tuto de Educação da Universidade do Minho. Esta linha, marcada pelo olhar antropológico, veio por um lado mostrar como poucos artefactos poderiam, tão bem quanto este, ilustrar a relação entre tradição e outras formas contemporâneas de pensar a arte, e, por outro, revelar todo o potencial teatral do Cabeçudo, já testado em exercícios performativos construídos na fronteira entre os campos visual, teatral e musical (CRUZ; LESSA; DIAS, 2008). Razões pelas quais volvemos a eles, a fim de estudar as possibilidades da relação entre teatro e tradição, porém eivado agora do sentido postmoderno, inscrito na ideia de “instalação” (TEDESCO, 2004).

A indução e a primeira abordagem à ideia de “instalação" partiram de uma outra Unidade Curricular, a de Puppetry, onde estratégias de desconstrução e ressignificação do objeto tinham sido desenvolvidas. Nesta unidade curricular, os estudantes construíram os Cabeçudos.

Experimentando o esqueleto do boneco, o Cabeçudo.

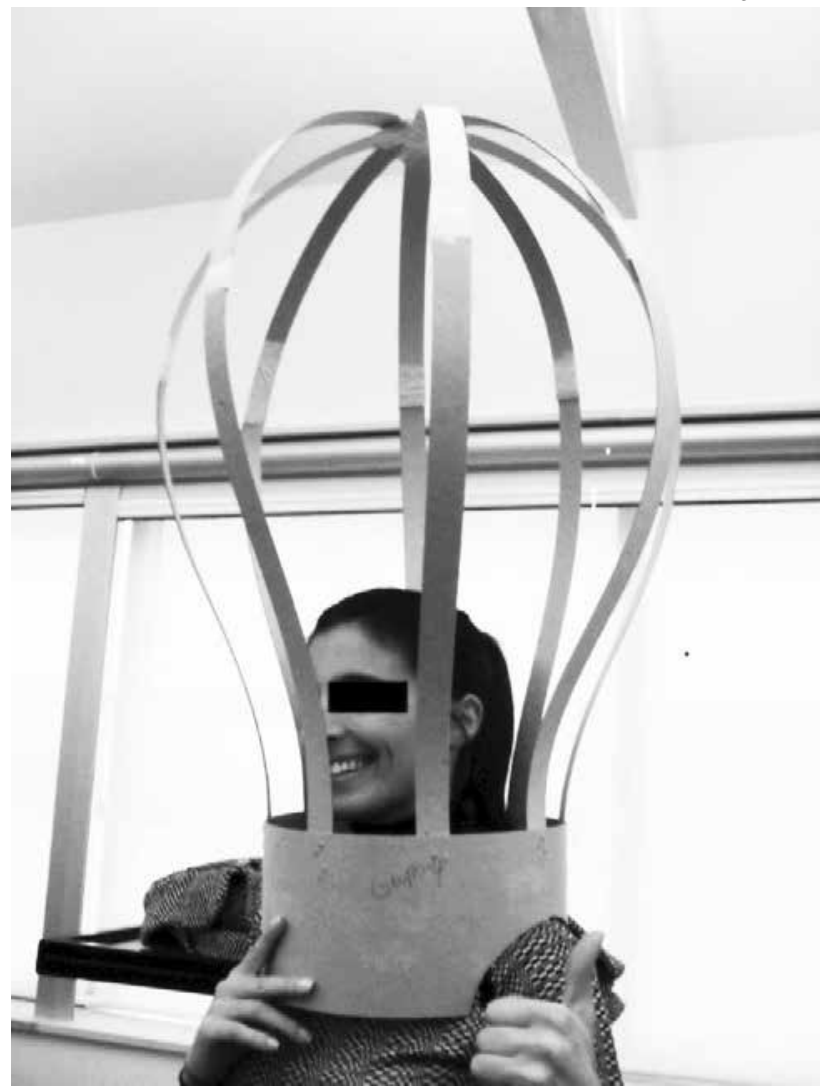

Fonte: Dias, 2011. 
A construção do esqueleto do boneco, o Cabeçudo, numa estrutura em cartão.

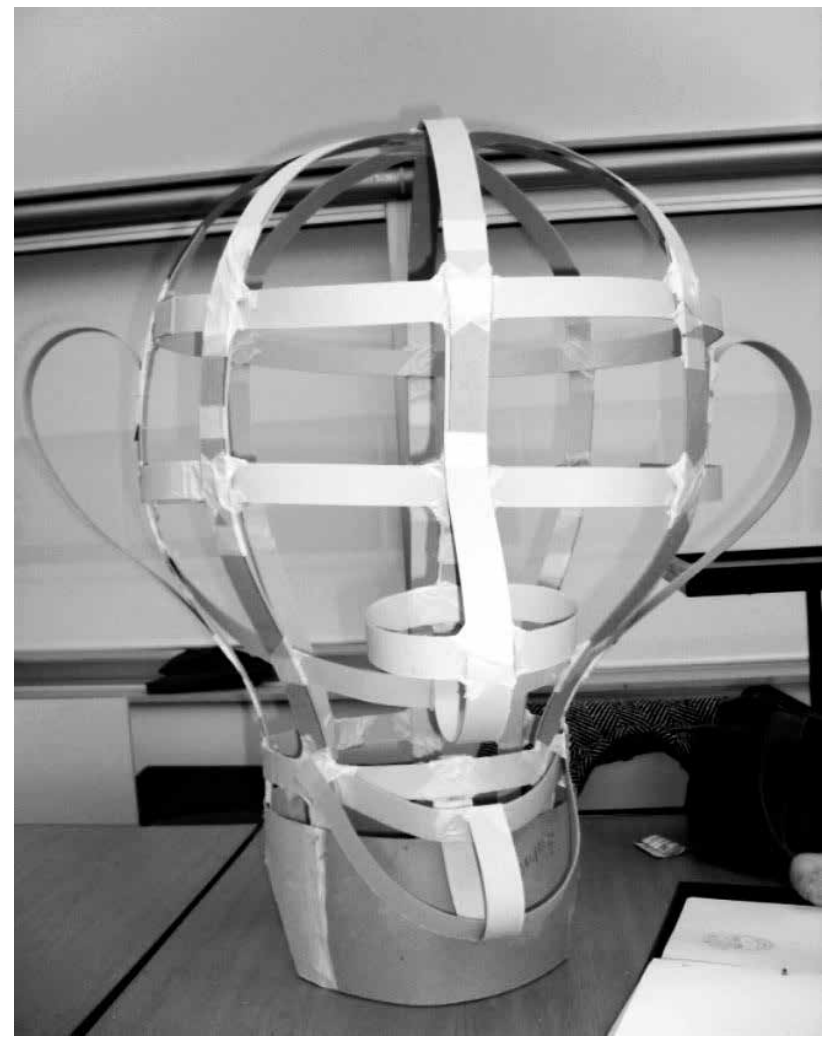

Fonte: Dias, 2011.

A fase da caracterização: a escolha do tipo de boneco e a modelação da fisionomia desejada.

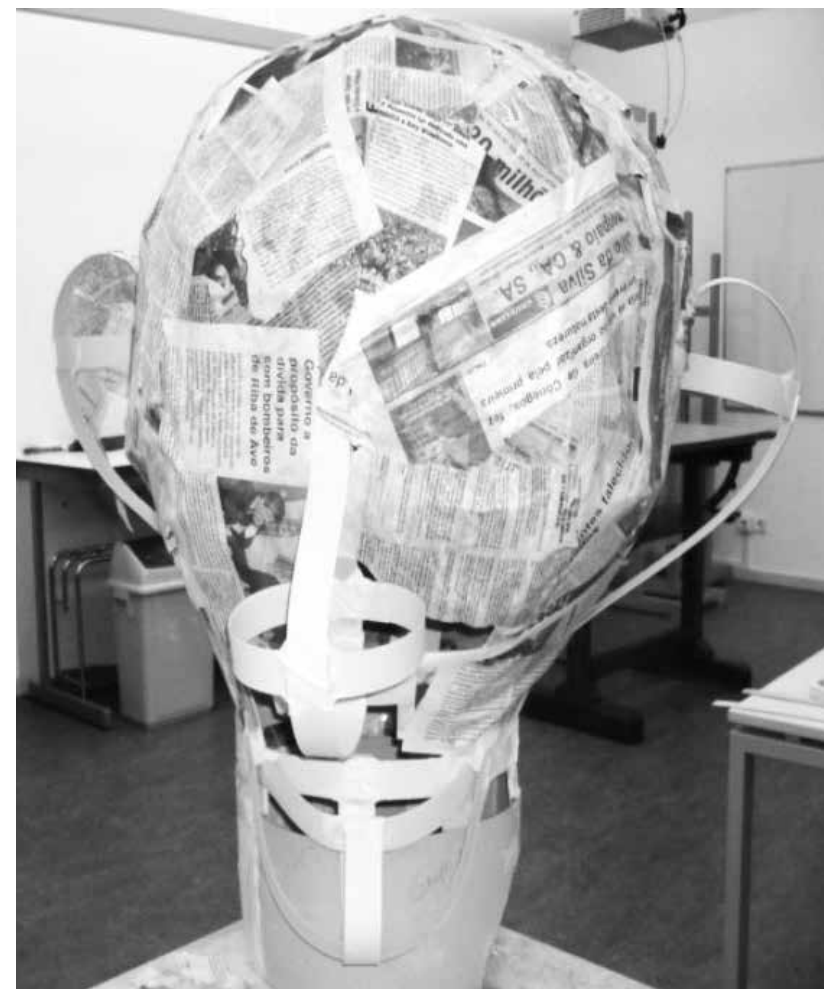

Fonte: Dias, 2011.
O Cabeçudo pintado e pronto para a confeção do seu traje.

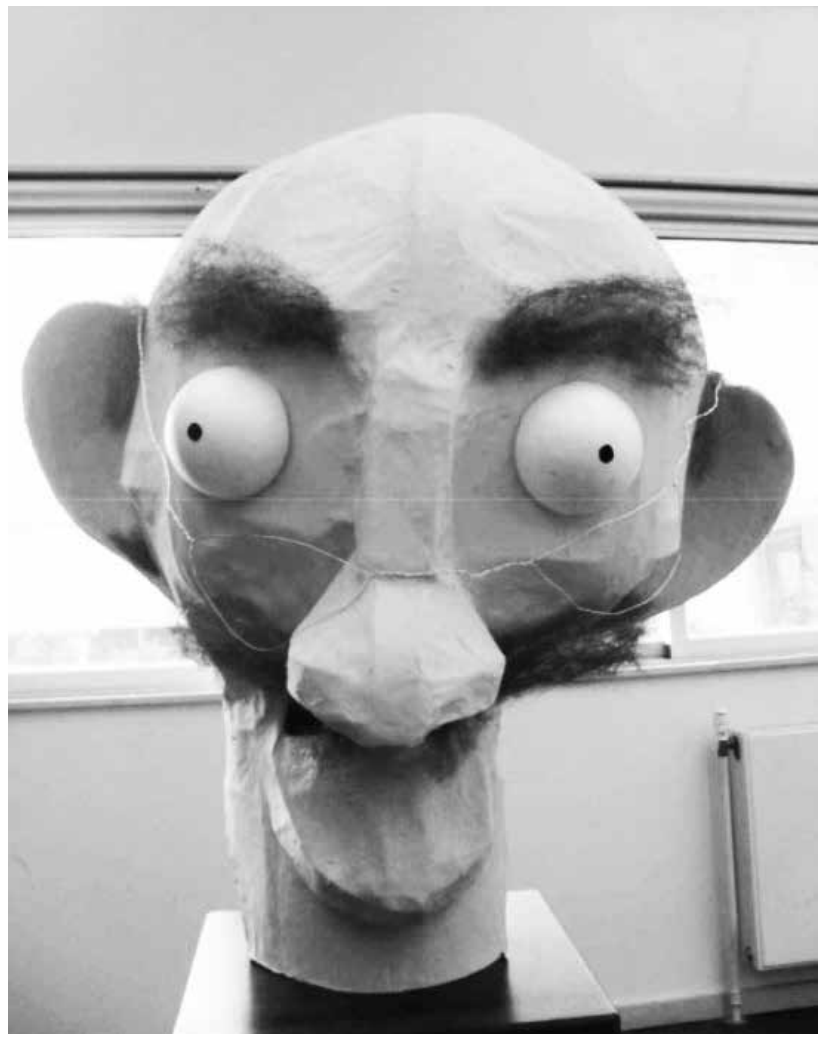

Fonte: Dias, 2011.

Nos diversos procedimentos de produção artística, à semelhança da apropriação ou ressignificação da imagem fotográfica, procurava-se a construção de um novo olhar sobre o Cabeçudo, assim como a sua posterior desconstrução. Os olhares vão sendo modificados, ao longo do processo, e a forma como são apropriados está intimamente ligada à questão da subjetividade, da possibilidade de criar significados. Neste contexto, o Cabeçudo testemunhava a relação entre a tradição e a forma contemporânea de pensar a arte, na busca pela reintegração ou atribuição de um novo significado ou mesmo pela simples difusão de um artefacto tradicional. $E$, retirado do seu contexto tradicional, proporcionaria, com certeza, uma nova significação, criaria novos sentidos.

Tradicionalmente, o cabeçudo estaria pronto para participar nos desfiles e procissões de rua onde desempenharia um papel de 
crítica social. No entanto, na etapa seguinte, individualização e "ressignificação" do cabeo professor sugeriu que fossem retirados dos çudo. A ideia de des-construir o modelo antitradicionais desfiles coletivos e colocados em go de uma procissão implica a necessidade de espaços não-convencionais, levando assim à criar cenários e atores não-convencionais.

o Cabeçudo em cenários não convencionais.
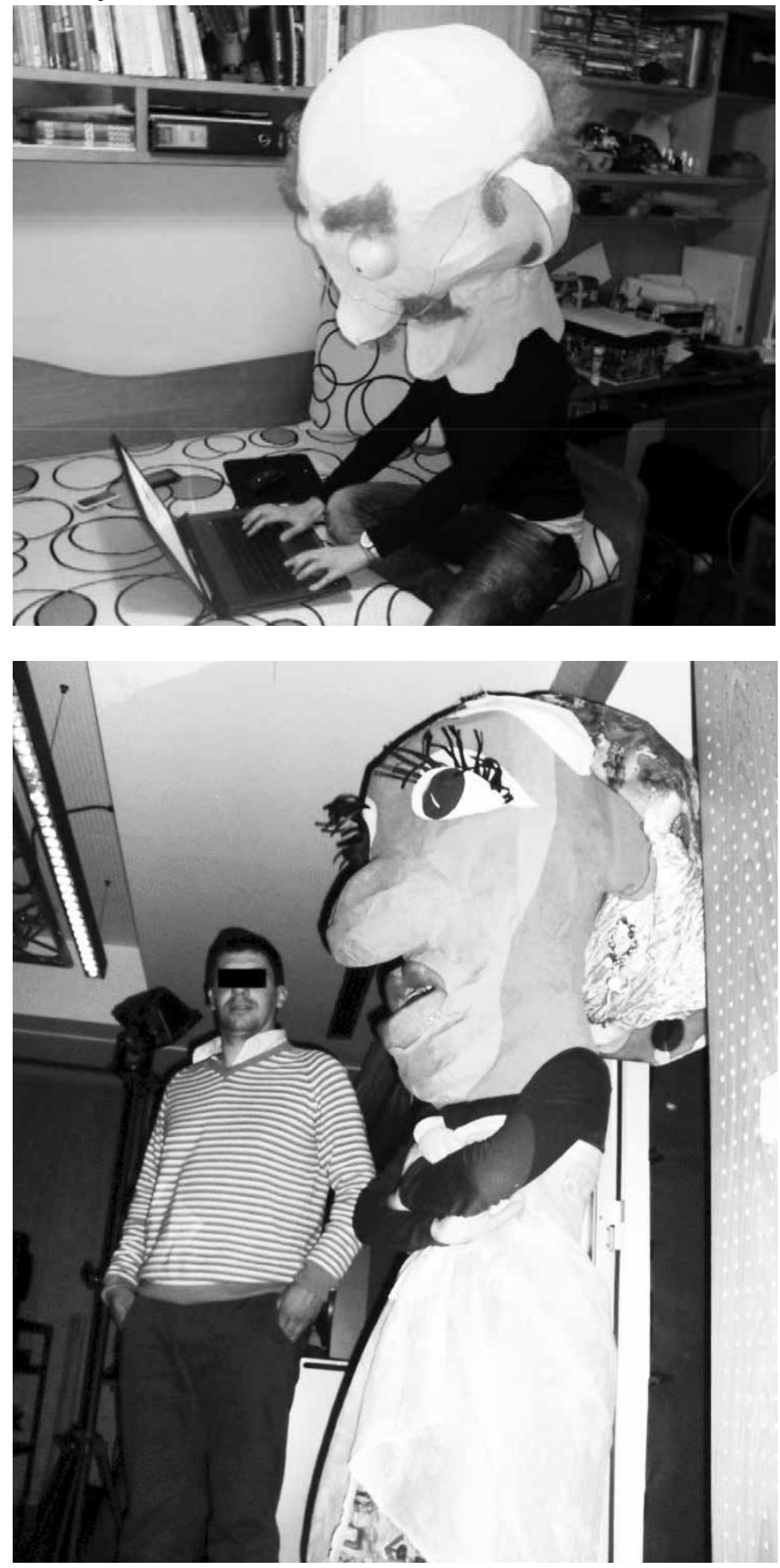

Fonte: Dias, 2011. 
Na senda e em articulação com os objetivos, movemos os Cabeçudos do espaço experimental do visual, para o "espaço vazio" de Brook (2008). Aí reinstalados, os Cabeçudos voltavam aos seus criadores, sujeitos a uma nova proposta exploratória, que os implicaria no seio da semântica e da dinâmica teatral.

Como refere Goldberg (1988, p. 20), a performance pode ser "preparada ou espontânea, com ou sem roteiro, improvisada ou ensaiada". Nesta situação específica, a proposta de pes- quisa teatral, não tendo roteiro explícito, nem guião esquadrinhado, não foi, contudo, de geração espontânea. Ela própria se foi determinando em cada grupo, ganhando sentidos, quer através da informação disponibilizada e do modo como essa informação interagiu com experiências e aprendizagens anteriores, quer pelo modo como esta foi sendo recepcionada e apropriada pelos formandos. Os textos então criados revelaram a capacidade dos grupos produzirem para cada artefacto novos significados e novas leituras.

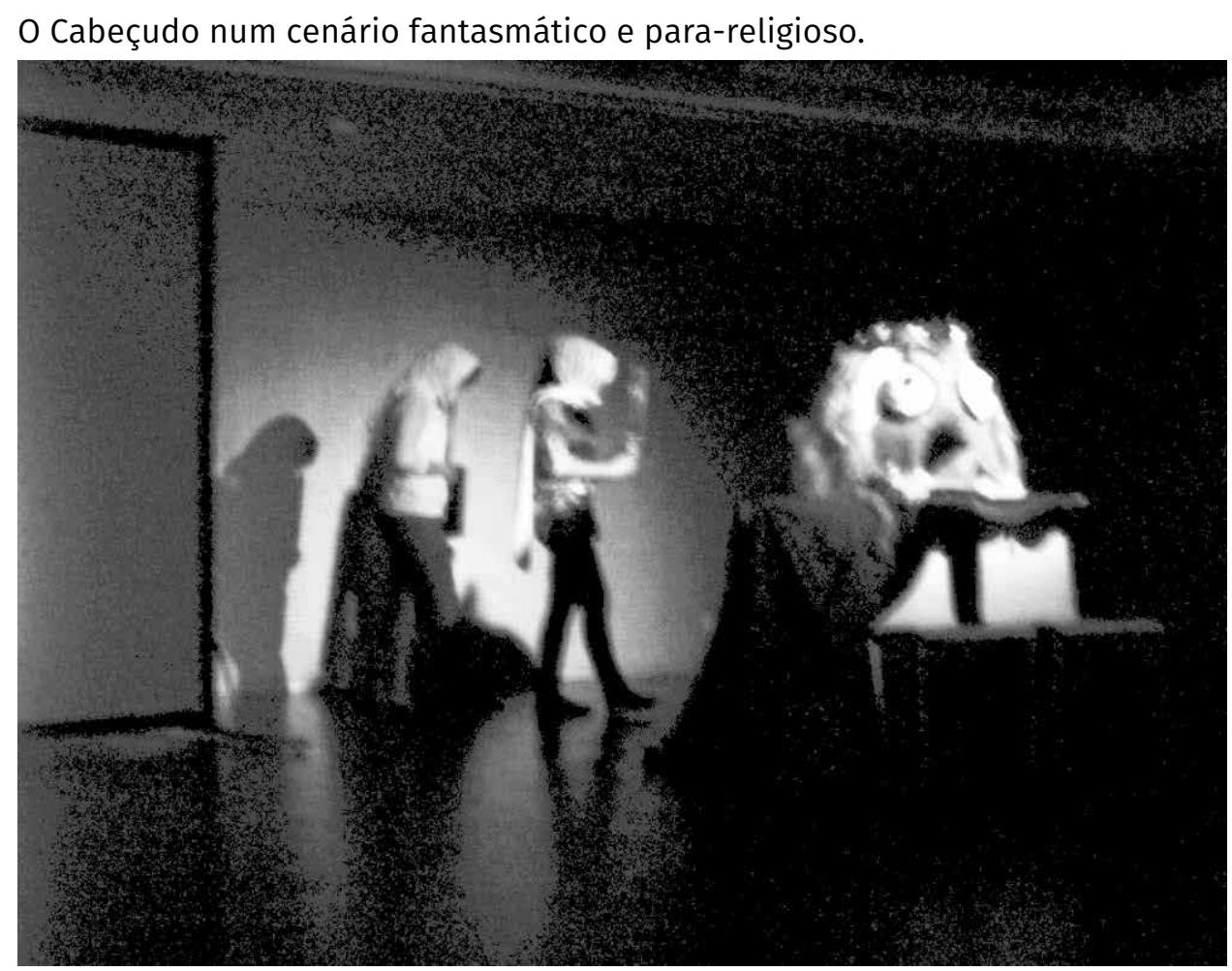

Fonte: Dias, 2011.

Nos processos exploratórios encetados os formandos encetados, os formandos apelaram a linguagens e metáforas de que resultaram três composições teatrais de sinal diverso:

1. Para uns, o Cabeçudo foi razão de criação de um universo fantasmático e para-religioso, que foi ganhando forma entre o jogo de luzes e o agigantar do corpo/cabeçudo. Uma construção que se transmutava ora num Deus medonhento ora em figuras dantescas que a intencionalidade da luz e da sua ausência fizeram projectar no vazio das paredes. A escolha da procissão (imagem arquetipal indissociável do passado religioso do (abeçudo) convidava aquele que a via, a posicionar-se - associar-se ou repelir - num tempo de evocação inquisitorial;

2. Para outros, o Cabeçudo foi motivo de uma construção estética prenhe de conflitos hipermodernos, onde a re- 
lação entre a imagem, objeto, som e corpo, instalaram sentidos de estranhamento, de surpresa, de repulsa e, principalmente, de estatismo. O tema da violência hipermediatizada materializou-se na instalação através do excesso e da gratuidade da própria violência: na ostensiva exposição da brutalidade, na obsessão pelo prazer que se adivinhava no esquartejamento do humano, no meticuloso desvelar das categorias simbólicas desse humano (criança e adulto), brutalmente desvelado no descabeçamento de bonecas e cabeçudos. Esta hiperexposição dos efeitos bélicos e bárbaros sobre o corpo, propostos na instalação, abria a um questionamento que remetia a assembleia para o esti- lhaçamento do direito à invulnerabilidade da memória e da intimidade do corpo da criança enquanto símbolo do humano;

3. Para outros, ainda, o Cabeçudo simbolizava a transgressão do religioso, o profano, a luxúria, num corpo masculino vestido de padre, meio despido, num cenário de bordel, onde dominava o vermelho e o preto, entre frutas e taças de vinho escorrendo. A lascívia e erotismo eram reforçados pela voluptuosidade da música e pela presença de corpos femininos, tentadores e provocantes, em corpetes de renda vermelhos e pretos que, num jogo de sedução, atraíam e eram atraídos pela figura do Cabeçudo.

o Cabeçudo num cenário de bordel, num corpo masculino vestido de padre, meio despido.

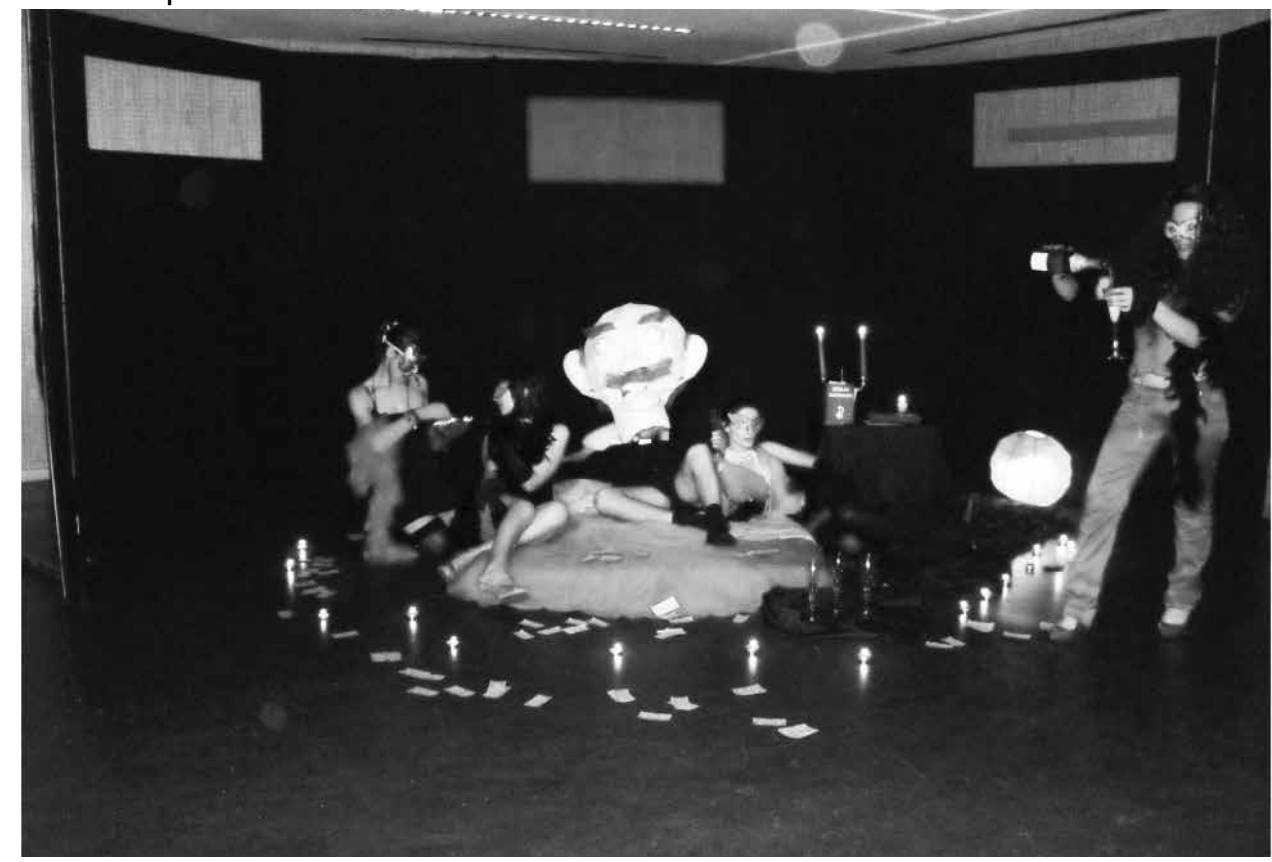

Fonte: Dias, 2011.

\section{Fecho}

A separação entre a formação do ator e a do animador teatral, útil para clarificar a identidade profissional de ambos, é uma questão que tem tanto de ambígua como de complexa. A profissão de animador teatral, não se alimentando exclusivamente dos saberes teatrais, tem, contudo, no instrumento Teatro, o signo maior da sua identidade profissional. 0 anima- 
dor, não sendo ator, necessita, como se o fosse, do saber e das ferramentas teatrais. Do domínio destas e da sua capacidade de as adequar aos contextos sociais, depende largamente a consciência da especificidade desta profissão. Sobretudo porque essa especificidade advém das necessidades de desenvolvimento e do envolvimento participativo de comunidades humanas onde o teatro é sobretudo lugar de encontro e de construção de pertença social.

Resulta deste paradoxo (de agir como se fosse, não sendo) a urgência de clarificar as representações sociais do que pode ser teatro, ator e público, de que os formandos, à entrada, são portadores.

A proposta de formação sobre a qual refletimos aponta para a alteração de algumas dessas representações. Alterações que não teriam sido possiveis se os formandos não tivessem passado, primeiro, por uma intensa exploração de um conjunto de ferramentas teatrais onde o corpo, a voz, o espaço e jogo dramático marcaram presença. Exploração, essa, que lhes proporcionou, no final do 1o semestre, avançar para um plano onde o "fazer teatral" se começava a plasmar na identidade de animador.

Importante, nesta mudança, parece ter sido o contributo da unidade curricular - Estudos Performativos. A convocação da plasticidade e do carácter interventivo da performance, transposto para a formação, permitiu desenvolver explorações múltiplas que abriram aos formandos a possibilidade de se confrontarem com as suas próprias crenças e de se posicionarem num jogo de alternâncias. Abriu-se, com o exercício da performance, a possibilidade de cada um experienciar a "artisticidade da ação", exercitando a sua própria consciência da "politicidade do corpo" (BARBA apud FABIÃO, 2008, p. 4). A observação, a partilha da criação com os outros e o feedback obtido na alternância entre o "serem atores" e constituírem-se como público/recetores do trabalho uns dos outros, transformou-se numa experiência de aprendizagem significativa onde a leitura individual e coletiva do mundo se uniam e ampliavam sentidos.

No balanço desta vivência, ao problematizar as metodologias utilizadas e ao refletir sobre as práticas, a questão de interrogar o quanto aquelas foram impactantes na dimensão pessoal e profissional dos próprios formadores foi ganhando relevância.

Para essa reflexão e, no que concerne à natureza do conhecimento profissional, tomamos como referencial a epistemologia da prática, sustentada por Schon (1983). Nesta perspetiva, o exercício docente, enquanto exercício profissional, é um "ato social, cultural e cientificamente específico, possui uma matriz que no caso dos professores, segundo Chaves (1997, p. 112), "o identifica e, simultaneamente o diferencia relativamente a outros". Muita desta distinção reside na natureza singular, incerta, dinâmica, multideterminada e naturalmente ambígua que determina a "ecologia circunstancial" da prática docente a que alude Schon (apud CHAVES, 1997, p. 111), quando se refere à profissão docente.

Pode-se então interrogar como, e quanto, a natureza desta matriz se extrema, ao se passar do ethos da formação docente para o ethos da formação docente em teatro, onde a subjetividade dos sujeitos, a ambiguidade veiculada pelas propostas, pelos objetos e pelas situações, se constituem, elas mesmas, no ingrediente secreto do saber fazer teatral.

Identificar e descriminar alguns dos fatores que envolvem a formação dos docentes parece ser importante, quer pelas implicações nos modelos e programas de formação, quer pelo contributo para a configuração dos perfis de competência que o desempenho profissional implica, quer, ainda, pelo empowerment que a reflexão sobre as práticas acarreta para o formador enquanto sujeito profissional. 
Fazer da performance o eixo de uma pedagogia teatral foi catalisar também o próprio processo de formação continuada como formadores. Surpreendentemente o trabalho com a performance encerrava em si mesmo um compromisso com um programa duplamente novo: novo para os alunos, como era suposto, inusitadamente novo para os sujeitos formadores.

À medida que a caixa de pandora se foi abrindo, a performance poria a nu dimensões que reconhecemos à posteriori, profundamente envoltas na natureza do exercício do conhecimento profissional, nomeadamente, no que concerne ao conhecimento que o formador tem de si mesmo, dos seus limites, da sua capacidade de resiliência, de parar no fio da

\section{Referências}

ASLAN, Odette. 0 ator no século XX. São Paulo: Perspectiva, 2010.

AUGÉ, Marc. Não-lugares. Introdução a uma metodologia da sobremodernidade. Lisboa: Letra Livre, 1995.

AZEVEDO, Sónia. O papel do corpo no corpo do ator. São Paulo: Perspectiva, 2002.

BARBA, Eugénio; SAVARESE, Nicola A arte secreta do ator - Um dicionário de antropologia teatral. São Paulo: Editora da Unicamp, 1995.

BROOK, Peter. 0 espaço vazio. Lisboa: Orfeu Negro, 2008.

CARDOSO, Carlos; LOPES, Marcelino; LEONIDO, Levi. Teatro na Educação. Vila Real: Ed. Fórum Ibérico, 2004.

CHARTIER, Roger. Cultura escrita, literatura e história. Trad. Reginaldo Carmello Corrêa de Moraes. Porto Alegre: Artmed, 2001.

CHAVES, Idália. A formação de professores numa perspetiva ecológica. Que fazer com esta circunstância? In: CHAVES, Idália, Percursos de formação e desenvolvimento profissional. Porto: Porto Editora, 1997. p. 108-117. navalha, do seu tempo de esperar pelo tempo do outro. De certo modo, a performance não só veio "turbinar a relação" (FABIÃO, 2010) dos formandos com a polis e com a realidade social, mas a própria relação dos formadores consigo mesmos.

Aceitar a evidência que não podíamos tudo, que não sabíamos tudo, que quase nada dependia de nós; prescindir da segurança do texto dado, integrar o circunstancial; acolher a leitura do outro; desprogramar uma ideia de corpo inscrevia-nos no "paradigma do inacabamento" que nos interpreta como seres em devir pessoal e profissional.

Determinar "o que não sabemos" é, no avesso, assumir que experienciámos a vertiginosa aventura da progressão do conhecimento.

COHEN, Renato. Performance como linguagem: criação de um tempo e espaço de experimentação. São Paulo: Editora Perspectiva, 1989.

COMISSÃO EUROPEIA. European Competitiveness Report 2010. Disponivel em: <http://bookshop. europa.eu/en/european-competitiveness-report-2010pbNBAK10001/> Acesso em: 11 jan. 2011.

CRUZ, Angélica; LESSA, Elisa; DIAS, Mạ Flor. Património Cultural e Globalização. 0 Caso das "Cabeçudas e Cabeçudos" do Minho. Cabeceiras de Basto: AGIR - Associação para a Investigação e Desenvolvimento Sócio-Cultural, 2008.

DIAS, Mạ Flor. Para Uma Genealogia da Educação Artística - História das disciplinas de Desenho, Trabalhos Manuais, Canto Coral e Educação pelo Teatro na escola primária portuguesa, do primeiro quartel do século XIX a meados do século XX. 2010. 370 f. Tese (Doutoramento em Educação Dramática) - Programa em Estudos da Criança: Instituto de Educação, Universidade do Minho, Braga, 2010.

FABIÃO, Eleonora. Performance e teatro: poéticas e políticas da cena contemporânea. Sala Preta, v. 8, p. 1-19, 2008. Disponivel em: <http://dx.doi. 
org/10.11606/issn.2238-3867.v8i0p235-246> Acesso em 10 out. 2010.

FÈrAL, Josette. Performance and Theatricality. Modern Drama, New York, v. 25, n. 1, p. 197-210, 1982.

GOLDBERG, Roselee. Performance art: from futurism to the present (World of Art). New York: Thames and Hudson, 1988.

GONÇALVES, Fernando; GONÇALVES, Tainá. Uso da fotografia em artes plásticas: memória e identidade em Alex Flemming e Rosângela Rennó. In: SIMPÓSIO DE PESQUISA EM COMUNICAÇÃO DA REGIÃO SUDESTE - SIPEC, 10., 2004, Rio de Janeiro. Anais... Rio de Janeiro: Sociedade Brasileira de Estudos Interdisciplinares da Comunicação Universidade do Estado do Rio de Janeiro, 2004. p. 1-9. Disponivel em: <http:// www.cac.uerj.br/files/o\%20uso\%20da\%20fotografia\%20em\%20artes\%20plasticas\%20-\%20fernando. pdf>. Acesso em: 10 out. 2010.

HARPER, Sarah. "Uma abordagem às implicações do envelhecimento global". in O Tempo da Vida Fórum Gulbenkian de Saúde sobre o Envelhecimento 2008|2009; Lisboa: Principia, 2009. 84.

KOSSOY, Boris. Estética, memória e ideologia fotográfica: decifrando a realidade interior das imagens do passado. Acervo: revista do ArquivoNacional, Rio de Janeiro, v. 6, n. 1/2, p. 13-24, jan./dez. 1993.

PAIS, José. Culturas Juvenis. 2. ed. Lisboa: Imprensa Nacional, 2003.

RANCIÈRE, Jean. 0 espectador emancipado. Lisboa: Orfeu Negro, 2010.

RENNÓ, Rosângela. 0 arquivo universal e outros ar- quivos. São Paulo: Cosac \& Naify, 2003.

RIBEIRO, António. Corpo a corpo: possibilidades e limites da crítica. Lisboa: Edições Cosmos, 1997.

SANTOS, Ma Lourdes. Indústrias culturais: especificidades e precariedades. OBS (Observatório das Actividades Culturais), n. 5, p. 2-6, 1994.

SCHON, Donald. The reflective practioner: how professional think in action. New York: Basic Books, 1983.

SILVA, Saulo. A imagem como meio de comunicação: a representação simbólica de uma realidade. Revista Espaço Académico, n. 85, p. 1-4, jun.2008. Disponivel em: <http://www.espacoacademico.com. br/085rea.htm>. Acesso em: 22 out. 2010.

SOUZA, Tânia. A análise do não verbal e os usos da imagem nos meios de comunicação. Ciberlegenda, n. 6, 65-94, 2001. Disponivel em: <http://www.uff.br/ mestcii/tania3.htm>. Acesso em: 22 out. 2010.

TEDESCO, Elaine. Instalação Campo de Relações, 2004. Disponivel em: <http://www.comum.com/ elainetedesco/pdfs/instalacao.pdf>. Acesso em: 26 fev. 2010.

VAN ERVEN, Eugene. Community theatre: global perspectives. London: Routledge, 2001.

VENTOSA, Victor. La expression dramática como médio de animación en educación social. Fundamentos técnicas y recursos. Salamanca: Amarú Editores, 1996.

Recebido em: 30.09.2016

Aprovado em: 23.01.2017

Maria Flor Dias é Doutora em Estudos da Criança, na Área de Especialização de Educação Dramática, pela Universidade do Minho e investigadora do Centro de Investigação em Estudos da Criança (CIEC). É Professora Auxiliar no Instituto de Educação da Universidade do Minho, na área de Educação e Expressão Dramática/Teatro, no Departamento de Teoria da Educação e Educação Artística e Física. e-mail: flor@ie.uminho.pt

Carla Pires Antunes é Doutora em Estudos da Criança, na Área de Especialização de Educação Dramática, pela Universidade do Minho e investigadora do Centro de Investigação em Estudos da Criança (CIEC). É Professora Auxiliar no Instituto de Educação da Universidade do Minho, na área de Educação e Expressão Dramática/Teatro, no Departamento de Teoria da Educação e Educação Artística e Física. e-mail: cmfapa@ie.uminho.pt

Instituto de Educação (IE), Universidade do Minho

Campus de Gualtar - 4710-057 - Braga - Portugal. Tel: 253604240 